\title{
Application of near infrared spectroscopy to estimate selected free amino acids and soluble nitrogen during cheese ripening
}

\author{
Jiří Mlček ${ }^{1}$, Otakar Rop ${ }^{1}$, Vlastimil Dohnal ${ }^{2}$, Květoslava Šustováa $^{2}$ \\ ${ }^{1}$ Tomas Bata University, Faculty of Technology, Department of Food Technology and Microbiology, \\ Zlín, Czech Republic, \\ ${ }^{2}$ Mendel University in Brno, Faculty of Agronomy, Department of Food Technology, \\ Brno, Czech Republic
}

Received October 15, 2010

Accepted September 13, 2011

\begin{abstract}
This paper deals with the estimation of tyrosine, tryptophan and soluble nitrogen in 288 samples of the Edam cheese using the Near Infrared Spectroscopy. For analyses, the apparatus NIR Nicolet Antaris was used working in the regime of reflectance (i.e. using an integrating sphere) in combination with fibre optics (i.e. using a probe). For calibration, reference data from the UV spectrophotometer was used. Calibration models were developed using a PLS algorithm (least square method) and tested by means of cross-validation. Correlation coefficients: $\mathrm{R}=0.911$, $\mathrm{R}=0.929$ and $\mathrm{R}=0.959$ for soluble nitrogen, tryptophan and tyrosine, respectively, were achieved during measuring in the integrating sphere; $R=0.807, R=0.945, R=0.928$ were achieved for soluble nitrogen, tryptophan and tyrosine, respectively, during measuring by probe. The results of the study show that NIR technology is suitable for fast and approximate determination of the level of cheese ripening. This can be used for the evaluation of the material for the processed cheese production, or cheese sale in optimal level of ripening.
\end{abstract}

NIR, Edam, tyrosine, tryptophan, proteolysis

Composition of young cheese is a key factor for further ageing. Similarly, the content of water represents one of the most important factors of regulation of curd hydrolysis and microbial growth in manufactured cheese. The near infrared spectroscopy shows a good predicting value when estimating fats, water content and proteins in natural and processed cheese and the obtained results correlate well with other reference methods (Rodriguezotero et al. 1995; McQueen et al. 1995; Mazerolles et al. 2000; Adamopoulos et al. 2001; McKenna 2001; Blaquez et al. 2004). These methods are of interest especially when monitoring the process of cheese ageing because they enable and facilitate, performing changes in the composition based on the results of analyses of young cheese. The composition of young cheese is a key to its further ageing and the moisture content is one of the most important factors of the regulation of curd hydrolysis and of cheese microbial growth. Nevertheless, changes and analysis of major compounds present in young cheese is not a good indicator of the course of its further ripening. The reason is that these cheese components are more or less unchanging and stable. On the other hand, however, changes in contents of peptides and free amino acids are very good indicators of cheese ageing. The cheese acquires its typical taste, smell, consistency and appearance only in the course of ageing, i.e. due to fermentation processes that change all three basic milk components, i.e. lactose, proteins and fat (Sustova et al. 2007; Drackova et al. 2008). Proteolysis is the most complex, and in the majority of cheese types, also one of the most important biochemical processes. Concentration of amino acids, a final product of proteolysis, is dependent on the type of cheese and stage of ageing. In Edam cheese, the most abundant amino acids include glutamine, leucine, arginine, lysine, phenylalanine and serine. The type and the quantity of free amino acids present in cheese influence its taste and provide information about the state of ageing and its progress. In the course of

Address for correspondence:

Ing. Jiří Mlček Ph.D.

Department of Food Technology and Microbiology,

Faculty of Technology, Tomas Bata University

Namesti T.G. Masaryka 275, 76272 Zlin, Czech Republic
Phone: +420576031529

Fax: +420 576031111

E-mail:mlcek@ft.utb.cz

http://www.vfu.cz/acta-vet/actavet.htm 
cheese ageing, concentrations of amino acids are increasing; the only exception to this rule is arginin whose concentration decreases in the final stage of ageing ( $\mathrm{McSw}$ eeney 2004). Free amino acids can substantially contribute to the taste of cheese as they make one of its sensory components (Lane et al. 1997). Good knowledge of the stage of cheese ageing is an important factor for its further development; besides, it is also a significant indicator for possible production of processed cheese. This study aims to consider the possibility of using NIR spectrometry to evaluate the stage of Edam cheese ripening.

\section{Materials and Methods}

Analyses were performed with cheese samples originating from two dairy factories. Each factory supplied 4 different types of Edam cheese; two of them contained $45 \%$ and $30 \%$ of fat in dry matter (FDM), and two contained the so-called starting cultures (Lactococcus lactis ssp. lactis, Lactococcus lactis ssp. cremoris and Lactococcus lactis subsp. cremoris, Lactococcus lactis subsp. lactis, Leuconostoc mesenteroides subsp. cremoris, Lactococcus lactis subsp. diacetylactis, Streptococcus thermophilus, Lactobacillus helveticus). Each sampling involved 3 samples. Analyses of these samples were performed in monthly intervals for up to 6 months. When cheese loaves were used, their central part (core) and crust were evaluated separately. The total number of cheese samples was 288. Every month, cheese samples were analysed for soluble nitrogen (N), soluble tyrosine (TYR) and tryptophan (TRP) with the objective to calibrate the FTIR apparatus with regard to individual components, which change in dependence on the degree of cheese ripeness (Table 1).

Table 1. Values of individual indicators in Edam cheese, established by reference methods $(\mathrm{n}=288)$

\begin{tabular}{lcccc}
\hline Indicator & Min & Max & $\mathrm{x}$ & SD \\
\hline $\mathrm{N}(\%$ from total N) & 5.18 & 18.79 & 12.43 & 3.26 \\
TRP $\left(\mathrm{mg} \cdot 100 \mathrm{~g}^{-1}\right)$ & $1.64 \cdot 10^{-2}$ & $5.16 \cdot 10^{-2}$ & $3.05 \cdot 10^{-2}$ & $7.38 \cdot 10^{-3}$ \\
TYR $\left(\mathrm{mg} \cdot 100 \mathrm{~g}^{-1}\right)$ & $2.46 \cdot 10^{-2}$ & $12.44 \cdot 10^{-2}$ & $7.15 \cdot 10^{-2}$ & $2.35 \cdot 10^{-2}$ \\
\hline
\end{tabular}

Max - maximum values; Min - minimum values; $\mathrm{x}$ - average values; SD - standard deviation; $\mathrm{N}$ - soluble nitrogen; TRP - tryptophan; TYR - tyrosine

Spectrophotometry determination of contents of tyrosin, tryptofan and soluble nitrogen according to the revised method of Vakaleris and Price (1959) was made in all samples of Edam cheese. Spectrophotometry determination was made in double-beam spectrophotometer UV (Visible Spectrometer Cintra 5, GBC Scientific Equipment, Australia). The cheese sample was homogenized with sodium citrate and water. Hydrochloric acid $(\mathrm{HCl})$ was added to this solution to reach the resultant $\mathrm{pH}$ in $4.35-4.45$ range. Thereafter, the samples were filtered. The blank sample was prepared from sodium citrate and $\mathrm{HCl}$. Extinction was measured in all filtrates with a wavelength of $270 \mathrm{~nm}$ and $290 \mathrm{~nm}$ in $1 \mathrm{~cm}$ cuvette in comparison with the blind sample. The contents of tyrosine, tryptofan and soluble nitrogen were counted according to the equation achieved from extinction value. Exact referential analyses of the samples are a limiting factor to obtaining functional calibration models (Murray 1986).

Samples of Edam cheese were analysed with near infrared spectrometer Nicolet Antaris using two different methods, either in the regime of reflectance in the integrating sphere (IS) of the apparatus with the accessory Sample Cup Spinner enabling the rotation of samples or using a fibre optic apparatus with the fibre optic probe. Spectra have been scanned within a range from 12500 to $4000 \mathrm{~cm}^{-1}$ for approximately $1 \mathrm{~min}$. When measuring, the fibre optic probe was placed directly on the surface of the sample which was $2-3 \mathrm{~cm}$ thick. This thickness enabled a safe reflectance of the beam. In individual samples, spectra were scanned twice from the core and twice from the crust of cheese loaf. For measurements in the integrating sphere, samples (approximately $5 \mathrm{~g}$ ) were grated and placed into a compression cuvette with a cup and glass bottom. Also in this case the central part of cheese loaf and its crust were grated and the spectra were repeatedly (i.e. twice) recorded. The number one spectrum recording was 80 scans with the spectral resolution 4, both for probe and integrating sphere. For evaluations the average spectrum was used.

Calibration models were created with the TQ Analyst version 6.2.1.509 (Thermo Electron Corporation, Madison, USA) software on the base of reference values and using mathematical-statistical methods of calculation. For calibration, the method of partial least squares (PLS) was used (Haaland et al. 1988a,b). The calibration model is tested by means of cross-validation because it provides an optimum number of PLS factors. Partial least squares factors used in calibration models include spectral and also concentration information. Cross-validation is used in order to avoid the so-called "overfitting" of calibration models (Sanderson et al. 1997). To obtain optimum calibration models for estimated components, adequate mathematical modification of recorded spectra was used and, simultaneously, also suitable wavelengths were selected. Evaluation of the results was performed based on the correlation between referential values and the values calculated from the obtained calibration formulas, and 
based on the value of standard deviations of the calibration (SEC) and validation (SEP). Standard deviations of the validation of reliable calibration is usually not much higher than SEC. The most desirable value of both deviations is a value close to zero. Another measure of reliability of the model is the value of calibration coefficient of variation $\mathrm{CCV}$ and the value of prediction coefficient of variation PCV. A very reliable calibration means that the value of CCV is below 5\% and the value of PCV is below 10\% (Esbensen 1998). Differences between reference and predicted NIR values were compared using the two-sample paired test of the mean value.

\section{Results}

Altogether 288 samples of Edam cheese were used to estimate tyrosine, tryptophan and soluble nitrogen. The results obtained by means of measurements performed in the integrating sphere and by means of probe were compared. None of these spectra were modified by derivation.

Numbers of PLS factors were high for all indicators under study. Lower PLS factors were found for soluble $\mathrm{N}$ because its concentrations were higher than those of soluble amino acids as it was more difficult to detect this dependency. The highest number of PLS factors was recorded for soluble tryptophan measured with the probe. It appears that these high values of PLS can also influence the quality of calibration models, mainly due to the fact that a high number of PLS factors reduces the prediction capacity.

After developing the calibration models, values of correlation coefficient of calibration were high. For developed models, values of correlation coefficients ranged from 0.807 to 0.959; standard deviations of calibration (SEC) were $2.53 \cdot 10^{-3} \mathrm{mg} \cdot 100 \mathrm{~g}^{-1}$ for the estimation of soluble tryptophan by means of probe and up to $1.91 \%$ of total $\mathrm{N}$ for the estimation of soluble $\mathrm{N}$ by means of probe (Table 2 ).

Table 2. Calibration and validation results of the individual indicators in Edam cheese, established by near infrared spectroscopy

\begin{tabular}{|c|c|c|c|c|c|c|}
\hline \multirow[t]{2}{*}{ Indicator } & \multicolumn{3}{|c|}{ Calibration } & \multicolumn{3}{|c|}{ Validation } \\
\hline & $\mathrm{R}$ & SEC & $\mathrm{CCV}(\%)$ & $\mathrm{R}$ & SEP & PCV (\%) \\
\hline $\mathrm{N}$ IS (\% from total N) & 0.911 & 1.33 & 10.79 & 0.881 & 1.53 & 12.41 \\
\hline $\mathrm{N}$ probe $(\%$ from total $\mathrm{N})$ & 0.807 & 1.91 & 15.35 & 0.762 & 2.1 & 16.88 \\
\hline TRP IS (mg·100 $\left.\mathrm{g}^{-1}\right)$ & 0.929 & $2.92 \cdot 10^{-3}$ & 10.14 & 0.854 & $4.12 \cdot 10^{-3}$ & 14.31 \\
\hline TRP probe $\left(\mathrm{mg} \cdot 100 \mathrm{~g}^{-1}\right)$ & 0.945 & $2.53 \cdot 10^{-3}$ & 8.78 & 0.821 & $4.49 \cdot 10^{-3}$ & 15.59 \\
\hline TYR IS (mg·100 g-1) & 0.959 & $7.04 \cdot 10^{-3}$ & 10.07 & 0.950 & $7.80 \cdot 10^{-3}$ & 11.16 \\
\hline TYR probe $\left(\mathrm{mg} \cdot 100 \mathrm{~g}^{-1}\right)$ & 0.928 & $9.25 \cdot 10^{-3}$ & 12.99 & 0.873 & $1.22 \cdot 10^{-2}$ & 17.13 \\
\hline
\end{tabular}

R - correlation coefficient; SEC - standard error of calibration; CCV - calibration coefficient of variation; SEP - standard error of prediction; PCV - prediction coefficient of variation; IS - integrating sphere; N - Soluble nitrogen; TRP - tryptophan; TYR - tyrosine

Following the test of model reliability, the $\mathrm{R}$ (validation) ranged from 0.762 to 0.950 and standard deviations of validation (SEP) were $4.12 \cdot 10^{-3} \mathrm{mg} \cdot 100 \mathrm{~g}^{-1}$ for the estimation of soluble tryptophan in the integrating sphere and up to $2.1 \%$ of total $\mathrm{N}$ for the estimation of soluble $\mathrm{N}$ by means of probe (Table 2). High variability was found for all calibrated components and values of CCV (from $8.78 \%$ to $15.35 \%$ ) and PCV (from $11.16 \%$ to $17.13 \%$ ) were higher than $5 \%$ and $10 \%$, respectively. This means that none of these models can be considered as reliable. Nevertheless, certain dependence was found so that they can be used for at least orientation estimation of individual indicators of ripening cheeses.

\section{Discussion}

Based on differences in values of correlation coefficients of calibration and validation, SEC and SEP, CCV and PCV, the most reliable model was developed for tyrosine measured 
in the integrating sphere $(\mathrm{CCV}=10.07 \%, \mathrm{PCV}=11.16 \%)$ and the least reliable one for soluble tryptophan measured by probe. In this case, the difference between coefficients was the highest $(\mathrm{CCV}=8.78 \%, \mathrm{PCV}=15.59 \%)$. The difference between reference and calculated values was tested by parametric paired $t$-test and no significant difference between reference values and $\operatorname{NIR}\left(\mathrm{t}_{\text {stat }}<\mathrm{t}_{\text {krit }}\right)$ was confirmed (Table 3$)$.

Table 3. Statistical evaluation of the individual indicators in Edam cheese, established by near infrared spectroscopy and reference methods by $t$-test

\begin{tabular}{lccccc}
\hline Indicator & $\mathrm{xREF}$ & $\mathrm{xNIR}$ & $\mathrm{t}_{\text {stat }}$ & $\mathrm{t}_{\text {krit }}(1)$ & $\mathrm{t}_{\text {krit }}(2)$ \\
\hline N IS $(\%$ from total N) & 12.332 & 12.332 & $-5.31 \cdot 10^{-3}$ & 1.9684 & 2.5934 \\
N probe $(\%$ from total N) & 12.442 & 12.442 & $-2.96 \cdot 10^{-3}$ & 1.9683 & 3.5932 \\
TRP IS (mg $100 \mathrm{~g}^{-1}$ ) & $2.88 \cdot 10^{-2}$ & $2.88 \cdot 10^{-2}$ & $-1.78 \cdot 10^{-2}$ & 1.9781 & 2.6136 \\
TRP probe $\left(\mathrm{mg} \cdot 100 \mathrm{~g}^{-1}\right)$ & $2.88 \cdot 10^{-2}$ & $2.88 \cdot 10^{-2}$ & $-6.90 \cdot 10^{-3}$ & 1.9784 & 2.6142 \\
TYR IS (mg $\left.100 \mathrm{~g} \mathrm{~g}^{-1}\right)$ & $6.99 \cdot 10^{-2}$ & $6.99 \cdot 10^{-2}$ & $2.07 \cdot 10^{-16}$ & 1.9718 & 2.6004 \\
TYR probe $\left(\mathrm{mg} \cdot 100 \mathrm{~g} \mathrm{~g}^{-1}\right)$ & $7.12 \cdot 10^{-2}$ & $7.12 \cdot 10^{-2}$ & $7.39 \cdot 10^{-3}$ & 1.9712 & 2.5992 \\
\hline
\end{tabular}

xREF - avarage of reference values, $\mathrm{xNIR}$ - average of NIR values; $\mathrm{t}_{\mathrm{stat}}$ - $\mathrm{t}$-test; $\mathrm{t}_{\mathrm{krit}}(1)$ - table value at $\alpha=0.05$; $\mathrm{t}_{\text {krit. }}(2)$ - table value at $\alpha=0.01$; IS - integrating sphere; $\mathrm{N}$ - soluble nitrogen; TRP - tryptophan; TYR - tyrosine

It can be therefore concluded that models developed based on measurements in the integrating sphere(IS) showed a better reliability than those developed based on measurement performed by a probe; this was obviously due to a higher degree of homogenisation and by the spinning of the sample in the integrating sphere. Values of correlation coefficients of calibration and validation were higher for IS and the differences between them were smaller than in probe measurements. Differences between SEC and SEP were also smaller.

Skeie et al. (2006) tried to estimate some individual free amino acids as well as their total sum during the process of the ageing of two Norwegian cheeses (Norwegia and Pråst). Their results show relatively good and fast predictive ability of NIR the technology for free amino acids determination during ripening. However, it is unlikely that NIR scanning can directly differentiate between the different amino acids in cheese since it is not possible to give a detailed interpretation of the spectra in individual amino acids.

Good knowledge of the stage of the natural cheese ripeness is important for the subsequent manufacturing of processed cheese. The type of cheese and the stage of its ripeness are very important for the consistence of the final product (Forman 1996). It is not recommended to use only cheese in higher stages of ripeness because there is a risk of decrease in the stiffness of the paste and a shift of rheological properties from elastic to viscous ones. Although processed cheeses are softer and can be spread more easily they also show increased stickiness to the wrapping. For that reason it is suitable to use the raw material (i.e. natural cheese) in an optimum stage of ripeness. Fox et al. (2004) summarised the defects of consistence of processed cheeses from the viewpoint of the use of natural cheeses in different stages of ripeness.

The estimation of free amino acids by means of UV spectrophotometry gave, as expected, less satisfying results mainly due to the fact that compared to the basic components of cheese, the accuracy of estimation of some less frequent compounds was lower. It is possible to recommend NIR spectroscopy for an orientation test and estimation of these substances mainly due to its speed. It could contribute not only to the evaluation of the degree of ripeness of Edam cheese, but also when selecting an optimum raw material for making processed cheeses. Performance of the NIRS method to predict free amino acids and soluble nitrogen during cheese ripening may be influenced by the accuracy of the referential method, against which the calibration is being performed. Usage of NIRS 
method may be further limited because it requires a demanding and difficult calibration. Once a reliable calibration is performed, the determination itself is very simple and without the need of any chemicals.

\section{Acknowledgement}

This study was supported by the Research Plan of the Ministry of Education, Youth and Sports of the Czech Republic 2B08069 National Research Plan - NPV II, plan 2B - Health and quality of life.

\section{References}

Adamopoulos KG, Goula AM, Petropakis HJ 2001: Quality control during processing of Feta cheese - NIR Application. J Food Compos Anal 14: 431-440

Blaquez C, Downey G, O'Donnell C, O'Callaghan D, Howard V 2004: Prediction of moisture, fat and inorganic salts in processed cheese by near infrared reflectance spectroscopy and multivariate data analysis. J Near Infrared Spec 12: 149-157

Drackova M, Hadra L, Janstova B, Navratilova P, Pridalova H, Vorlova L 2008: Analysis of goat milk by nearinfrared spectroscopy. Acta Vet Brno 77: 415-422

Esbensen K 1998: Multivariate analysis-in practise, Camo ASA, 157 p.

Forman L 1996: Dairy technology II. VŠCHT Praha, 228 p.

Fox P 2004: Cheese: chemistry, physics, and microbiology. Elsevier, Amsterdam, 617 p.

Lane CN, Fox PF, Johnston DE, McSweeney PLH 1997: Contribution of coagulant to proteolysis and textural changes in Cheddar cheese during ripening. Int Dairy J 7: 453-464

Haaland MD, Thomas VE 1988a: Partial least squares methods for spectral analyses. 1. Relation to other quantitative calibration methods and the extraction of qualitative information. Anal Chem 60: 1193-1202

Haaland MD, Thomas VE 1988b: Partial least squares methods for spectral analyses. 2. Application to simulated and glass spectral data. Anal Chem 60: 1193-1202

Mazerolles G, Duboz G, Hugot S 2000: Moisture and fat content determination in hard and semi-hard cheeses by near infrared spectroscopy in transmission mode. Le Lait 80: 371-379

McKenna D, 2001: Measuring moisture in cheese by near infrared absorption spectroscopy. J AOAC Int 84: 623-628

McQueen DH, Wilson R, Kinnunen A, Jensen EP 1995: Comparison of two infrared spectroscopic methods for cheese analysis. Talanta 42: 2007-2015

McSweeney PLH 2004: Biochemistry of cheese ripening: introduction and overview. Int J Dairy Technol 57: 347-357

Murray I 1986: Near infrared reflectance analysis of forages. In W. Heresign and D. J. A. Cole (Eds.), Recent advances in animal nutrition, London: Butterworths, 141-156 p.

Rodriguezotero JL, Hermida M, Cepeda A 1995: Determination of fat, protein, and total solids in cheese by nearinfrared reflectance spectroscopy. J AOAC Int 78: 802-806

Sanderson R, Lister SJ, Dhanoa MS, Barnes RJ, Thomas C 1997: Use of near infrared reflectance spectroscopy to predict and compare the composition of carcass samples from young steers. Anim Sci 65: 45-54

Skeie S, Feten G, Almøy T, Østlie H, Isaksson T 2006: The use of near infrared spectroscopy to predict selected free amino acids during cheese ripening. Int Dairy J 16: 236-242

Sustova K, Ruzickova J, Kuchtik J 2007: Application of FT near spectroscopy for determination of true protein and casein in milk. Czech J Anim Sci 52: 284-291

Vakaleris DG, Price WV 1959: A rapid spectrophotometric method for measuring cheese ripening. J Dairy Sci 42: 264-276 